\title{
INVESTIGANDO PROCESSOS DE AUTORIA NA PRODUÇÃO DO RELATÓRIO DE INICIAÇÃO CIENTÍFICA DE UM GRADUANDO EM QUÍMICA
}

\author{
Analyzing authorship processes in the production \\ of a research report written by \\ an undergraduate Chemistry student
}

Luciana Massi ${ }^{1}$. Salete Linhares Queiroz ${ }^{2}$

\begin{abstract}
Resumo: Neste trabalho, analisamos o relatório de Iniciação Científica produzido por um aluno de graduação em Química, a partir da perspectiva da Análise de Discurso de linha francesa, como vem sendo divulgada por Eni Orlandi, especialmente quanto à noção de autoria. Orlandi distingue três tipos de repetição no processo de autoria: empírica, formal e histórica. Percebemos, na produção do relatório, o exercício da repetição empírica e formal, além do uso da repetição histórica, que demonstra a posição de autor ocupada pelo aluno. Essa investigação nos levou à percepção sobre a influência da Iniciação Científica na apropriação da linguagem científica, e indicou que esse processo se deu por meio da troca com os pares, da imitação de modelos, e, sobretudo, da vivência da pesquisa.
\end{abstract}

Palavras-chave: Análise do discurso. Autoria. Iniciação científica. Química.

\begin{abstract}
In this work we analyse a research report written by an undergraduate chemistry student, from the perspective of French Discourse Analysis, as formulated by Eni Orlandi, specifically the concept of authorship. Orlandi differentiates three types of repetition in the authorship process: empirical, formal, and historical. Concerning the concept of authorship, we realized that in the development of the report there was the exercise of empirical and formal repetition. Besides that, the use of historical repetition which demonstrates the author's position, that occupied by the student was also observed. Therefore, this research led us to an awareness of the influence of undergraduate research in the appropriation of scientific language and indicated that this process occurred through exchanges among peers, the imitation of patterns, and mainly the research experience.
\end{abstract}

Keywords: Discourse analysis. Authorship. Undergraduate Research. Chemistry.

\footnotetext{
${ }^{1}$ Instituto de Química de São Carlos, Universidade de São Paulo (USP).

${ }^{2}$ Departamento de Físico Química, Instituto de Química de São Carlos, USP. Av. Trab. São-carlense, 400, Caixa Postal 780. São Carlos, SP, Brasil. 13.560-970. salete@iqsc.usp.br
} 
Massi, L.; Queiroz, S. L.

\section{Introdução}

Desde a década de 1950, foram instituídos, por agências de fomento, programas de incentivo à pesquisa científica na graduação. No entanto, existem poucos trabalhos na literatura interessados em investigar a atividade da Iniciação Científica (IC) desenvolvida no Brasil, conforme constatamos em levantamento bibliográfico realizado sobre o assunto (MASSI; QUEIROZ, 2010). Especificamente na área de Química, destacamos o trabalho de Queiroz e Almeida (2004), que investigaram o entendimento de bolsistas submetidos à IC, no que diz respeito à natureza da ciência. Segundo as autoras, a "imersão" dos alunos no laboratório de pesquisa trouxe grandes benefícios para a sua formação: a permanência constante e participativa no local onde se produz a ciência criou condições invejáveis que, provavelmente, proporcionaram a compreensão, para os alunos, de como se faz ciência e a iniciação à arte de fazer ciência.

Surpreendentemente, poucos pesquisadores (BRIDI, 2004; QUEIROZ; ALMEIDA, 2004) se preocuparam em investigar o que acreditamos ser uma das principais contribuições advindas da realização da IC: o contato amiúde dos bolsistas com diversas formas de veiculação dos conteúdos científicos. Supomos que esse contato pode vir a favorecer a apropriação da linguagem científica por parte dos estudantes e, consequentemente, o desenvolvimento das suas habilidades de comunicação oral e escrita no campo científico. Desta forma, neste trabalho, utilizamos a Análise do Discurso (AD) de linha francesa, discutida no Brasil, sobretudo, por Eni Orlandi $(2000,2003,2004)$, como referencial teórico para investigar a relação entre a IC e a apropriação da linguagem científica.

Durante o período de um ano, acompanhamos um graduando em Química, iniciando seu estágio de IC em laboratório de pesquisa de uma universidade estadual paulista, seguindo os preceitos das pesquisas qualitativas do tipo etnográfico. Ao longo desse período de acompanhamento, coletamos dados relacionados: aos diálogos por ele estabelecidos com outros membros do laboratório; às suas anotações no caderno de laboratório; ao seu relatório de pesquisa apresentado ao Conselho Nacional de Desenvolvimento Científico e Tecnológico (CNPq); e ao trabalho escrito por ele e apresentado em formato de painel no Congresso de Iniciação Científica, promovido pela universidade na qual atuou como bolsista.

Todos os envolvidos na pesquisa tiveram sua identidade preservada, por isso, os nomes citados no texto são fictícios. Neste trabalho, analisamos o relatório científico intitulado Medidas de bidrofobicidade da parede celular de leveduras por adesão a bidrocarbonetos: diferentes leveduras, bidrocarbonetos e meios de suspensão de células, produzido pelo aluno Eduardo, sob orientação de Pedro (formalmente seu coorientador), com relação à noção de autoria, advinda das pesquisas de Eni Orlandi (2004).

\section{Análise do Discurso de Linha Francesa}

A AD tem como objeto o discurso, entendido como palavra em movimento e prática de linguagem. Ela analisa o sentido, ao invés do significado, e o modo de funcionamento dos discursos, ao invés da interpretação. Esse trabalho com o discurso implica a construção de sentidos com base nas suas condições de produção, entendidas, no sentido mais estrito, como sendo o contexto imediato da enunciação, e, em um sentido mais amplo, podem incluir o contexto sócio-histórico - ideológico. É justamente nesse segundo contexto que podem ser 
apreendidos os efeitos de sentidos. Assim, as palavras mudam de sentido segundo as posições daqueles que as empregam, elas tiram seu sentido dessas posições, isto é, em relação às formações nas quais essas posições se inscrevem. A formação discursiva caracteriza-se, então, como uma matriz do sentido: ela dita as regras para que o que o sujeito pode e deve dizer no âmbito de suas práticas sociais e, até mesmo, para aquilo que não pode e não deve ser dito. Para compreender o funcionamento dos discursos, é também fundamental considerar que há um já-dito, uma memória discursiva entendida como interdiscurso. Há uma relação entre o já-dito e o que está sendo dito, da mesma forma que existe uma relação entre o interdiscurso e o intradiscurso. O interdiscurso é todo conjunto de formulações feitas e já esquecidas que determinam o que dizemos. Enquanto o intradiscurso se encontra no nível da formulação e representa o fio do discurso, o funcionamento do discurso em relação a ele mesmo (ORLANDI, 2003).

Em uma situação de produção de discursos, entendemos que "o sujeito tem de inserir seu dizer no repetível (interdiscurso, memória discursiva) para que seja interpretável” (ORLANDI, 2004, p. 48). Essa inscrição do dizer no repetível histórico e sua relação com a interpretação são fundamentais para a constituição do autor - que supõe a repetição e a interpretação. Nessa situação, embora "o autor se constitua pela repetição, esta é parte da história e não mero exercício mnemônico" (ORLANDI, 2004, p. 69). Para Orlandi (2004) o sujeito só exerce a função-autor quando historiciza seu dizer, num jogo com a memória discursiva diretamente ligado à interpretação. Em suas palavras "o sujeito só se faz autor se o que ele produz for interpretável" (ORLANDI, 2004, p. 70), se ele "inscreve sua formulação no interdiscurso, ele historiciza seu dizer" (ORLANDI, 2004, p. 70). Assim, o autor consegue formular, no interior do formulável, e se constituir, com seu enunciado, numa história de formulações (ORLANDI, 2004).

Nesse contexto, Orlandi (2004) distingue a repetição empírica, a repetição formal e a repetição histórica. A repetição empírica refere-se ao exercício mnemônico, em que o indivíduo repete exatamente da forma como leu ou ouviu. A repetição formal trata do exercício gramatical, em que o indivíduo repete o que leu ou ouviu de maneira um pouco diferenciada, muda as frases, isto é, diz a mesma coisa com palavras diferentes. Tanto na repetição empírica quanto na repetição formal o trabalho com o discurso se dá no nível do intradiscurso. Por outro lado, na repetição histórica, ocorre a interpretação, pois o repetível aqui faz parte da memória constitutiva do sujeito, ele consegue formular e constituir seu enunciado no interior das repetições. Ou seja, o autor traz outros textos, traz o interdiscurso pelo exercício da memória, costurando o texto original com os outros enunciados trazidos pelo enunciador. Apenas na repetição histórica o indivíduo se constitui enquanto autor do texto, pois historiciza seu dizer, trabalha com um lugar de interpretação definido pela relação com o "Outro" (interdiscurso) e o "outro" (interlocutor).

Neste trabalho investigamos como se dá a relação entre os chamados "textos primeiros" (FOUCAULT, 2004), que serviram de referência (memória discursiva) para a elaboração do relatório, e os deslocamentos e inserções de sentidos, empregados pelo aluno no processo de redação do documento científico destinado à agência de fomento. A partir dessas relações foi possível reconhecer processos de autoria de acordo com a distinção proposta por Orlandi (2004) entre as repetições empíricas, formais e históricas.

Em se tratando do discurso científico, objeto de nossa análise, devemos considerar as condições de produção e as formações discursivas que fundamentam a produção textual em análise. De maneira geral, podemos considerar que existe certa rigidez associada à produção de 
Massi, L.; Queiroz, S. L.

textos em um espaço estabilizado, no qual os sentidos são únicos. No jogo da ciência, existem várias regras implícitas que devem ser respeitadas pelos enunciadores. Segundo Orlandi (2004, p. 139), "o cientista está submetido à memória de seu saber". Portanto, para observar os processos de autoria e o jogo discursivo da tipologia, tivemos em mente que os alunos estavam

Inseridos num contexto sócio-histórico, atravessados, portanto, por uma ideologia, pertencendo a uma determinada formação discursiva, enfim, em certas condições de produção, os sujeitos-enunciadores buscam incessantemente produzir sentido. Dentre essas condições de produção, manifestação do jogo ideológico da ciência, destacam-se o espaço material reservado para o texto, as regras impostas pela revista, ou pela comunidade científica a que pertencem, e as chamadas condições situacionais de comunicação (em que cada enunciador idealiza o outro um imagina os conhecimentos do outro, ideologias, opiniões, etc. -, formula o seu objetivo - intenção do ato comunicativo entendido aqui nos dois sentidos: produção e compreensão - e constrói o seu texto adaptando-o a cada um desses fatores). (CORACINI, 1991, p. 190)

Nesse contexto, entendemos ainda que o uso dos diferentes tipos de repetição e o exercício da função-autor estejam relacionados com a compreensão, assimilação e apropriação do conhecimento científico. Apontando, assim, para uma relação entre linguagem e cognição. Ao produzir textos científicos segundo as regras da ciência, que, muitas vezes, implica uma manutenção dos sentidos, acreditamos que o autor revele sua apropriação da linguagem científica. Desta forma, embora a repetição empírica e a formal não apontem para o exercício da função autor, elas têm papel importante no contexto de produção de textos científicos, em que nem sempre a reprodução é desvalorizada e pode ser entendida como indício de compreensão e assimilação da formação discursiva própria da ciência. Por outro lado, a repetição histórica apontaria não apenas para o exercício da função autor, mas para a produção de conhecimento científico, como destacado por Orlandi (2004, p. 139): "transferir: produzir novas versões, efeitos metafóricos, deslizamentos de sentidos, que permitam o avanço científico". Ressaltamos, ainda, que o texto foi revisado pelo coorientador, e por meio dessa discussão podemos verificar a adequação dos discursos produzidos em relação à formação discursiva da ciência.

\section{Processo de produção do relatório científico do aluno Eduardo}

O relatório do aluno Eduardo, redigido no intervalo de aproximadamente um mês, trata dos dados por ele coletados no decorrer do ano no qual realizamos o acompanhamento no laboratório. Para acompanharmos a produção do texto, solicitamos que o aluno salvasse cada arquivo produzido sem sobrepor as informações novas; dessa forma, observamos um total de 12 arquivos produzidos no editor de textos Word® ${ }^{\circledR}$ com várias etapas e versões, que conduziram à produção do relatório final. Acompanhamos todas as etapas e tivemos acesso a todas as versões, o que nos permitiu uma boa visão sobre o processo de produção do relatório e viabilizou o nosso trabalho de análise. Em quase todas as versões iniciais, as correções de 
Investigando processos de autoria na produção ...

Pedro eram feitas na forma oral e por meio de orientações gerais, a partir das quais o aluno revisava toda a produção; em uma das últimas versões, Pedro fez correções escritas no texto impresso do arquivo produzido pelo aluno, à qual também tivemos acesso.

Para obter a primeira versão do relatório, Eduardo dividiu sua tarefa em dois grandes segmentos: a produção e análise dos gráficos obtidos, que viria a se tornar a seção de resultados e discussão; e a produção do texto, para as seções de introdução e de materiais e métodos.

A produção e análise dos gráficos obtidos se deu em três etapas, nas quais o aluno acrescentava informações ou produzia alterações a partir das sugestões de Pedro. Seguindo as orientações de Pedro, a primeira etapa desse processo consistiu na inserção dos gráficos no editor de textos Wordâ; além dessa inserção, Eduardo apenas esboçou uma legenda simples para cada gráfico. Na segunda e terceira etapas do processo, Eduardo introduziu alterações no texto inicial produzido na etapa anterior; as alterações advinham de algumas sugestões de Pedro sobre o texto, tais como: a inserção da tabela com os dados numéricos sobre o gráfico e uma descrição dos pontos obtidos. As etapas seguintes consistem de novas alterações nessa última versão, produzidas a partir das considerações de Pedro.

A produção do texto para as seções introdução e materiais e métodos também se deu em algumas etapas; em cada uma delas Eduardo produziu seu texto a partir do relatório de uma bolsista que desenvolveu pesquisa no laboratório, como Pedro havia sugerido.

Após concluir a produção e análise dos gráficos e a produção do texto para as seções de introdução e de materiais e métodos, a primeira versão do relatório estava pronta. Pedro uniu os arquivos em um só e formatou o texto, devolvendo-o a Eduardo com algumas indicações de correções, sendo que, a partir das novas alterações, Eduardo e Pedro chegaram à versão final do relatório, que foi enviada à agência de fomento.

A versão final do relatório continha 37 páginas, divididas nas seções clássicas de um relatório de pesquisa, como discutido por Oliveira e Queiroz (2007): introdução, materiais e métodos, objetivo, resultados, discussão e conclusão, referências bibliográficas. Sendo a introdução subdividida nos tópicos: hidrofobicidade, flotação, superfície das células de levedura, meio de cultivo e composição da parede celular, métodos de medida de hidrofobicidade. A seção materiais e métodos se dividiu em: linhagens, meios de cultivo e propagação das linhagens e medição da hidrofobicidade por partição em sistema de duas fases. Os resultados também foram subdivididos em relação às linhagens de leveduras e aos meios de cultivo.

Como mencionado anteriormente, Eduardo deu continuidade a um projeto iniciado por outra aluna de IC, sendo que o relatório dessa aluna serviu de base para o seu texto. Assim, verificamos as relações entre esse texto primeiro e as respectivas etapas e versões do relatório de Eduardo, na tentativa de reconhecermos a ocorrência das repetições empírica, formal e histórica. A seguir, discutimos tais ocorrências nas versões do relatório em questão.

\section{Análise do relatório científico do aluno Eduardo - repetição empírica}

$\mathrm{Na}$ repetição empírica, temos o exercício mnemônico de repetição palavra por palavra, observada no nível do intradiscurso. Foram observadas poucas ocorrências desse tipo de repetição em trechos da introdução, nos quais o aluno reproduziu parágrafos do relatório da aluna de IC na íntegra. Além da introdução, observamos a repetição empírica na seção de materiais e métodos. 
Massi, L.; Queiroz, S. L.

As leveduras foram propagadas em meio definido (modificado por DeSousa \& Laluce, 2000) contendo os macro-nutrientes g/L: 20 de glicose, 3,12 de $\mathrm{NH}_{4} \mathrm{SO}_{4}, 1,99$ de $\mathrm{KH}_{2} \mathrm{PO}_{4}$, 0,54 de $\mathrm{MgSO}_{4} .7 \mathrm{H}_{2} \mathrm{O}, 0,09$ de $\mathrm{CaCl}_{2}$ e 0,11 de $\mathrm{NaCl}$; vitaminas: 30,0 de myo-inositol, 4,8 de piroxidina, 1,68 de tiamina, 4,8 de pantetonato de cálcio, 0,36 de biotina e micro-nutrientes $\mathrm{mg} / \mathrm{L}: 72,8$ de $\mathrm{ZnSO}_{4}$.7H2O, 10,4 de CuSO $.5 \mathrm{H} 2 \mathrm{O}, 10,4$ de $\mathrm{H}_{3} \mathrm{BO}_{3}, 52,0$ de $\mathrm{FeCl}_{3} .6 \mathrm{H}_{2} \mathrm{O}$, 10,4 de KI.o meio foi esterelizado por 20 minutos em autoclave (fabricada pela Fabbe-Primar Industrial LTDA, modelo 103) pelo vapor produzido a $120{ }^{\circ} \mathrm{C}$ e atmosfera de pressão.

Nessa seção não se espera que alterações consideráveis existam nos trabalhos dos membros de um mesmo grupo de pesquisa (OLIVEIRA; QUEIROZ, 2007). No entanto, como apresentado acima, um dos parágrafos do texto original foi copiado palavra por palavra por Eduardo, incluindo informações como o modelo e marca do equipamento e o uso do símbolo ${ }^{\circ}$ utilizado incorretamente para indicar graus Celsius $\left({ }^{\circ} \mathrm{C}\right)$. Esse erro foi corrigido por Pedro na versão final do relatório. Outro erro, copiado do relatório da bolsista, que não foi percebido por Eduardo ou Pedro e que permaneceu na versão definitiva, foi a ausência de espaço e letra maiúscula no início da última frase (destacada no trecho acima).

Podemos especular que a repetição empírica, em alguns trechos da seção de materiais e métodos, se deva à concordância do aluno no que diz respeito a informações contidas no relatório original, associada ao fato de esse procedimento de escrita ser habitual em muitos laboratórios. Em contrapartida, tal repetição na seção de introdução não é esperada, sugerindo a dificuldade do aluno em se expressar na linguagem científica adequada para essa seção. De fato, além das repetições empíricas, o aluno introduziu alterações, nem que fossem apenas de ordem gramatical, em alguns trechos dessa seção, realizando uma repetição formal, conforme discutiremos a seguir.

\section{Análise do relatório científico do aluno Eduardo - repetição formal}

A maior parte da introdução e alguns trechos da seção materiais e métodos foram marcados pela repetição formal, no entanto observamos repetições de três naturezas distintas. Em sua primeira natureza, a repetição formal cumpria uma função explicativa, quando, por exemplo, o aluno trocava palavras de forma a ligar as frases de um mesmo parágrafo, de certa maneira introduzindo um novo sentido; em outras situações, a substituição de palavras e a inversão da ordem das mesmas na frase produzia novos sentidos que não concordavam com o sentido original, e que poderiam se configurar em erro quanto ao rigor científico; no terceiro caso, o aluno removia partes do texto ou realizava pequenas trocas para adaptar o texto original aos dados específicos do seu projeto de pesquisa.

Observamos, na primeira natureza, uma função explicativa da repetição formal, quando o aluno substituiu algumas palavras do texto original e inseriu novos termos, destacados no trecho abaixo, produzindo um efeito de ligação entre as frases do seguinte parágrafo: 
Investigando processos de autoria na produção ...

\begin{tabular}{|c|c|}
\hline Parágrafo do texto original & Parágrafo do relatório final de Eduardo \\
\hline $\begin{array}{l}\text { Essa tendência à repulsão entre superfícies, na maio- } \\
\text { ria das vezes, é determinada em relação à tendência } \\
\text { de atração individual e da diversidade de grupos hidro- } \\
\text { fóbicos, como se a força de atração pela água fosse } \\
\text { menor do que as demais forças envolvidas (tendência } \\
\text { à adesão). A adesão dos grupos hidrofóbicos às de- } \\
\text { mais superfícies existentes no sistema aquoso preva- } \\
\text { lece sobre a tendência de repulsão à água, daí a corre- } \\
\text { lação existente entre o fenômeno da hidrofobicidade e } \\
\text { da adesão. Na estabilização de sistemas aquosos as } \\
\text { interações hidrofóbicas desempenham um papel pre- } \\
\text { dominante sobre adesão de grupos não polares } \\
\text { (Stumm, 1992). }\end{array}$ & $\begin{array}{l}\text { Essa tendência à repulsão, na maioria das vezes, é } \\
\text { determinada em comparação com a tendência de atra- } \\
\text { ção individual e da diversidade de grupos hidrofóbicos, } \\
\text { como se a força de atração pela água fosse menor do } \\
\text { que as demais forças envolvidas (tendência à adesão) } \\
\text { Ou seja, a adesão dos grupos hidrofóbicos às demais } \\
\text { superfícies existentes no sistema aquoso prevalece } \\
\text { sobre a tendência de repulsão à água, daí a correlação } \\
\text { existente entre o fenômeno da hidrofobicidade e da } \\
\text { adesão. Como na estabilização de sistemas aquosos } \\
\text { onde as interações hidrofóbicas desempenham um } \\
\text { papel predominante na adesão de grupos não polares } \\
\text { (Stumm, 1992). }\end{array}$ \\
\hline
\end{tabular}

Apesar da maior parte do trecho se constituir no exercício mnemônico, acreditamos que as palavras introduzidas no texto deslocaram o sentido original no nível do intradiscurso por meio da troca entre as palavras relação e comparação, e pela ligação entre as frases agora iniciadas pelas expressões ou seja e como. Observamos, nessa situação, uma preocupação do bolsista em tornar o texto mais claro, e, para tanto, imaginamos que o aluno compreendeu o sentido para poder introduzir as alterações sem que essas se configurem em erros.

\begin{tabular}{|c|c|}
\hline Parágrafo do texto original & Parágrafo do relatório final de Eduardo \\
\hline $\begin{array}{l}\text { Sabe-se que a hidrofobicidade da parede celular mi- } \\
\text { crobiana depaende de suas propriedades físico-quí- } \\
\text { micas que dependem da composição da mesma. Esta } \\
\text { composição varia em função da espécie do microrga- } \\
\text { nismo e das condições de cultivo - meio de cultura, } \\
\text { fase do crescimento e temperatura (Van Haecht et al., } \\
\text { 1982). }\end{array}$ & $\begin{array}{l}\text { Sabe-se que a hidrofobicidade da parede celular } \\
\text { microbiana depende de suas propriedades físico- } \\
\text { químicas influenciadas pela composição da mesma } \\
\text { Esta composição varia em função da espécie individua } \\
\text { e das condições de cultivo do microrganismo - meio } \\
\text { de cultura, fase do crescimento, temperatura (Van } \\
\text { Haecht et al., 1982). }\end{array}$ \\
\hline
\end{tabular}

No trecho acima, percebemos outros exemplos de como essas pequenas alterações no intradiscurso facilitam a leitura - por melhorarem a linguagem utilizada, evitando a repetição do verbo depender - e a compreensão do texto, pela introdução de termos explicativos, como individual, e pela alteração da expressão do microorganismo.

Outro exemplo de repetição formal, ainda considerado como primeira natureza, que observamos no relatório, se refere à ordem global dos títulos e subtítulos do texto de Eduardo e no trabalho original, que dava um enfoque maior à correlação entre as medidas de hidrofobicidade e a flotação. Apresentamos, no Quadro 1, a comparação entre a organização dos dois relatórios. 
Massi, L.; Queiroz, S. L.

Quadro 1. Disposição dos temas no relatório da bolsista anterior e no relatório de Eduardo.

\begin{tabular}{|c|c|}
\hline Disposição dos temas no texto original & Disposição dos temas no relatório do Eduardo \\
\hline $\begin{array}{l}\text { 1.1 Fatores que influenciam no processo de } \\
\text { flotação } \\
\text { 1.1.1 Formação e estabilidade da espuma } \\
\text { 1.1.2 A superfície das células de levedura } \\
\text { 1.2 As forças de interações nas interfaces } \\
\text { 1.2.1 Força eletrostática } \\
\text { 1.2.2 Hidrofobicidade } \\
\text { 1.2.2.1 Adesão microbiana } \\
\text { 1.2.2.2 Meio de cultivo e composição da } \\
\text { parede celular. } \\
\text { 1.2.2.3 Métodos de medida da hidrofobicidade } \\
\text { 1.3 Técnicas convencionais de flotação, } \\
\text { equipamentos e processos } \\
\text { 1.3.1 Coluna de flotação }\end{array}$ & $\begin{array}{l}\text { 1.1. Hidrofobicidade } \\
\text { 1.2. Flotação } \\
\text { 1.3. A superfície das células de levedura } \\
\text { 1.3.1. Adesão microbiana } \\
\text { 1.4. Meio de cultivo e composição da parede celular } \\
\text { 1.5. Métodos de medida de hidrofobicidade }\end{array}$ \\
\hline
\end{tabular}

Fonte: As autoras.

Percebemos que o aluno manteve os mesmos títulos, excluiu vários subitens e também abordou os temas meio de cultivo e composição da parede celular e métodos de medida de bidrofobicidade como títulos separados, ao invés de colocar como subtítulos para o tema hidrofobicidade, como no relatório original. Essas alterações foram consideradas como exemplos de repetição formal, devido à alteração da ordem e exclusão de itens.

A segunda natureza da repetição formal introduz alterações no nível gramatical, que deslocam o sentido de forma mais significativa. Esses deslocamentos, eventualmente, podem se configurar em erros ou, ainda, se constituir numa perda de precisão.

\begin{tabular}{|l|c|}
\hline \multicolumn{1}{|c|}{ Parágrafo do texto original } & Parágrafo do relatório final de Eduardo \\
\hline $\begin{array}{l}\text { O uso da flotação como processo de separação de } \\
\text { células em sistemas biológicos depende da identifica- } \\
\text { ção e esclarecimentos sobre a ação de agentes de ati- } \\
\text { vação da flotação, sua repressão e a toxicidade des- } \\
\text { tes agentes sobre os microorganismos. }\end{array}$ & $\begin{array}{l}\text { A aplicação da flotação como processo de separação } \\
\text { de células em sistemas biológicos depende da identifi- } \\
\text { cação e esclarecimentos sobre a ação de agentes de } \\
\text { ativação e repressão do processo. }\end{array}$ \\
\hline
\end{tabular}

Observamos, no trecho acima, a construção do texto do relatório a partir da seleção de algumas passagens do texto original. No entanto, as alterações produzidas (destacadas no texto) excluem aspectos relevantes sobre o tipo de informação necessária para o uso, substituída pela aplicaşão, da flotação. Outro exemplo de exclusão de um trecho do texto original pode ser observado na comparação abaixo.

\begin{tabular}{|c|c|}
\hline Parágrafo do texto original & Parágrafo do relatório final de Eduardo \\
\hline $\begin{array}{l}\text { A flotação é um processo de separação de partículas } \\
\text { suspensas em meio líquido baseado na propriedade } \\
\text { da adesão das mesmas em interfaces sólido-líquido. }\end{array}$ & $\begin{array}{l}\text { A flotação é um processo de separação de partículas } \\
\text { hidrofóbicas suspensas em meio líquido baseado na } \\
\text { propriedade da interface sólido-líquido. }\end{array}$ \\
\hline
\end{tabular}


Percebemos que o aluno altera o sentido inicial de que a flotação se baseia na propriedade de adesão das partículas em interfaces para, por meio da exclusão da passagem da adesão das mesmas em, introduzir o sentido de que a flotação se baseia na propriedade da interface. Apesar de o aluno não produzir aqui um erro, ele exclui o sentido original que marca o papel da adesão das partículas na promoção da remoção das partículas que estavam suspensas em meio líquido.

\begin{tabular}{|c|c|}
\hline Parágrafo do texto original & Parágrafo do relatório final de Eduardo \\
\hline $\begin{array}{l}\text { Apesar das controvérsias descritas na literatura, quanto } \\
\text { à escolha do melhor método (Ahimou et al., 2001), a } \\
\text { hidrofobicidade é usualmente determinada por partição } \\
\text { em um sistema de duas fases (fase aquosa/fase orgâ- } \\
\text { nica), no qual o grau de hidrofobicidade é medido pela } \\
\text { adesão das células a hidrocarbonetos (Rosemberg, } \\
\text { 1991). Van der Mei et al. (1995) afirma que esta técni- } \\
\text { ca é extremamente útil, como um simples ensaio para } \\
\text { estudar a adesão de microrganismos a uma superfície } \\
\text { hidrofóbica, mas é essencialmente diferente de um } \\
\text { ensaio típico de hidrofobicidade. }\end{array}$ & $\begin{array}{l}\text { Apesar de estarem descritas na literatura controvérsi- } \\
\text { as quanto à escolha do melhor método (Ahimou et al., } \\
\text { 2001), a hidrofobicidade é usualmente determinada por } \\
\text { partição em um sistema de duas fases, constituída por } \\
\text { fase aquosa/fase orgânica (Rosemberg, 1991), forne- } \\
\text { cendo como resultado o grau de adesão de células a } \\
\text { hidrocarbonetos. Van der Mei et al. (1995) defende que } \\
\text { esta técnica é extremamente útil como um simples en- } \\
\text { saio para estudar a adesão de microrganismos a uma } \\
\text { superfície hidrofóbica o que é claro, essencialmente } \\
\text { diferente de ser um ensaio sobre hidrofobicidade. }\end{array}$ \\
\hline
\end{tabular}

Observamos o mesmo tipo de deslocamento no trecho acima, mas, nesse caso, além das alterações na posição da palavra controvérsias e das alterações gramaticais, como a troca de afirma por defende, e a exclusão dos parênteses, o aluno omite a passagem bidrofobicidade é medido pela, que indicava, no texto original, o sentido de que o grau de hidrofobicidade era medido pela adesão de células hidrocarbonetos; enquanto, a partir da alteração de Eduardo, o sentido muda e remete à ideia de que a técnica de partição fornece, como resultado, o grau de adesão, e não mais o grau de hidrofobicidade. Observamos outra alteração de sentido quando o aluno substitui o termo mas, que dá a ideia de contraposição, pela expressão o que é claro, que traz outro sentido à frase. Destacamos, também, a inversão na posição da referência ao trabalho do autor Rosemberg - esse tipo de alteração será discutido no parágrafo seguinte; no trecho seguinte, o aluno trabalhou com a repetição formal com maior liberdade, dessa forma, correndo mais riscos de incorrer em erros.

\begin{tabular}{|l|l|}
\hline \multicolumn{1}{|c|}{ Parágrafo do texto original } & \multicolumn{1}{|c|}{ Parágrafo do relatório final de Eduardo } \\
\hline $\begin{array}{l}\text { As propriedades físico-químicas de adesão e hidrofo- } \\
\text { bicidade manifestadas na superfície das células go- } \\
\text { vernam uma série de fenômenos amplamente empre- } \\
\text { gados em indústrias de bebidas e na área de enge- } \\
\text { nharia (Sharma, 2001) }\end{array}$ & $\begin{array}{l}\text { As propriedades físico-químicas de adesão e hidrofo- } \\
\text { bicidade manifestadas na superfície das células go- } \\
\text { vernam uma série de fenômenos amplamente empre- } \\
\text { gados industrialmente (Sharma, 2001) }\end{array}$ \\
\hline
\end{tabular}

O aluno deslocou a posição da referência, alterando a sintaxe da sentença, e introduzindo um novo sentido sobre o tipo de informação que constava no trabalho da referência, no caso, o trabalho do autor Sharma. No texto original, temos a impressão de que esse trata da aplicação das propriedades físico-químicas da adesão e hidrofobicidade em indústrias, especi- 
Massi, L.; Queiroz, S. L.

ficamente nas indústrias de bebidas e engenharia; enquanto, no parágrafo alterado, temos a impressão de que o trabalho de Sharma descreve os fenômenos governados pelas propriedades físico-químicas, que são empregados industrialmente. A partir do acompanhamento do processo de produção do relatório, acreditamos que o aluno não consultou o trabalho original do autor, até porque, no mesmo período em que foi feita a alteração, Eduardo questionou Pedro sobre "o que significavam aquelas palavras e numeros grifados em negrito no relatório da bolsista anterior", indicando que o aluno não sabia identificar uma citação bibliográfica e, portanto, não imaginava que a disposição dela no texto produzisse tal deslocamento de sentido, por nós descrito.

Outra situação na qual observamos esses movimentos no texto foi quando o aluno trocou o termo aglutinabilidade celular pelo termo agregação celular em uma frase, sendo que essa continha uma citação bibliográfica. Novamente, sabemos que o aluno não consultou o trabalho citado, sendo esse tipo de substituição problemática, especialmente em disciplinas nas quais termos relativamente similares podem ter significados diferentes. Pensando apenas na questão semântica, percebemos que o termo aglutinabilidade se refere a uma capacidade de aglutinação, que difere do sentido de agregação, que remete a um fato concluído. Além disso, aglutinar traz a noção de unir e grudar, enquanto agregar traz a ideia de ajuntar. Não podemos dizer qual foi a motivação do sujeito, nem cabe à análise entrar nesse tipo de questão, mas talvez, novamente, essa troca revele uma preocupação didática, visto que o termo agregação é mais conhecido, ou, ainda, revele uma preocupação gramatical, tendo em vista que o texto foi produzido no editor de textos Word $^{\circledR}$ e o corretor ortográfico desse software não reconhece o termo aglutinabilidade, indicando o erro para o produtor do texto.

A terceira e última natureza de repetição formal que observamos no relatório de Eduardo pode ser visualizada na seção de materiais e métodos, na qual percebemos que o aluno seguiu toda a organização do relatório original, tendo apenas retirado as informações que não eram condizentes com sua pesquisa.

\section{Análise do relatório científico do aluno Eduardo - repetição histórica}

A repetição histórica se refere ao jogo com a memória discursiva que introduz novas informações e, portanto, o interdiscurso no texto. Observamos, na análise, a ocorrência de repetições históricas de duas naturezas distintas.

A primeira natureza de repetição histórica foi observada nas alterações do relatório da bolsista anterior que o aluno implementou para adequar as passagens às particularidades do seu projeto de pesquisa. Lembramos que, nesse tipo de alteração, o aluno fez uso tanto da repetição formal, que já foi discutida, como da repetição histórica, que aqui será abordada. A segunda natureza de repetição histórica foi observada nas partes do relatório que foram produzidas pelo aluno, sem que ele estivesse preso ao texto original; consideramos que, nesse caso, o aluno produziu o texto de forma livre, pelo fato de que esses textos não estavam baseados no relatório da bolsista anterior. Situações como essa foram observadas em alguns subitens da seção de materiais e métodos e na seção dos resultados, visto que, na introdução, observamos a predominância das repetições formal e empírica. Como era de se esperar, observamos, nesses textos livres, algumas correções de Pedro, que, na maioria dos casos, consistiam em substituição de palavras visando uma melhor adequação à linguagem científica. Essas correções também serão discutidas neste subitem. 
Investigando processos de autoria na produção ...

Nesta parte da análise, as duas naturezas de repetição histórica, que nós observamos e descrevemos acima, não serão apresentadas segmentadas (como fizemos na apresentação dos tipos de repetição formal), considerando que a observação dessas naturezas de repetição também não se deu de forma diferenciada. Assim, trazemos, nessa seção, as naturezas alternadas e, em alguns casos, até mesmo misturadas na mesma passagem analisada, como produzido pelo aluno.

Inicialmente, trazemos um exemplo de repetição histórica encontrada na introdução do relatório. Destacamos, neste exemplo, a alteração da definição da hidrofobicidade, sem a inserção de uma referência.

\begin{tabular}{|c|c|}
\hline Parágrafo do texto original & Parágrafo do relatório final de Eduardo \\
\hline $\begin{array}{l}\text { A hidrofobicidade é uma propriedade físico-química } \\
\text { que se refere a uma aversão da superfície pela água. }\end{array}$ & $\begin{array}{l}\text { A hidrofobicidade é uma propriedade físico-química que } \\
\text { se refere à capacidade que uma substância, em meio } \\
\text { aquoso, de aderir a um solvente majoritariamente apolar. }\end{array}$ \\
\hline
\end{tabular}

Acreditamos que essa substituição favoreça uma adequação do termo ao projeto de pesquisa do aluno, que envolve, diretamente, o uso de diferentes solventes apolares; dessa forma, se referir à hidrofobicidade como uma capacidade de a substância aderir a um solvente majoritariamente apolar, estaria mais próximo da situação que o aluno observou na prática do que a definição da hidrofobicidade como uma aversão pela água. Pela precisão dos termos, pressupomos que o aluno deve ter baseado sua definição nos textos básicos de físico-química, os quais ele costumava procurar na biblioteca para compreender melhor o seu trabalho, segundo nos relatou. Esse tipo de substituição é um exemplo claro de repetição histórica, pois o aluno introduz o interdiscurso, pelo jogo com a memória discursiva, no eixo do intradiscurso (ORLANDI, 2004).

Ainda na introdução do relatório, encontramos um exemplo de repetição histórica que indica a busca de informações nas referências citadas no texto, o que poderíamos considerar um interdiscurso mostrado ou revelado. Tivemos acesso aos artigos que o aluno consultou para a elaboração do relatório e percebemos, na frase transcrita abaixo, que ele complementou as informações do texto original, introduzindo termos que davam maior precisão científica.

\begin{tabular}{|l|l|}
\hline \multicolumn{1}{|c|}{ Parágrafo do texto original } & \multicolumn{1}{|c|}{ Parágrafo do relatório final de Eduardo } \\
\hline $\begin{array}{l}\text { Espécies individuais de leveduras apresentam diferen- } \\
\text { ças quanto a componentes simples ligados como o } \\
\text { fosfato, amônia e potássio (Mozes et al., 1988). }\end{array}$ & $\begin{array}{l}\text { Espécies individuais de leveduras apresentam diferen- } \\
\text { ças quanto à constituição da parede celular em rela- } \\
\text { ção ao componente fosfato, amônia e potássio (Mo- } \\
\text { zes, N., Leonard, A.J., Rouxhet, P. G., 1988). }\end{array}$ \\
\hline
\end{tabular}

Nesse caso, observamos a introdução do trecho sobre a localização dos componentes químicos fosfato, amônia e potássio, na parede celular, e não simplesmente ligados (não se sabe a que), como presente no texto original. Além dessa alteração que se baseou na consulta ao artigo, o aluno também alterou a forma de apresentação da citação, substituindo o termo et al. 
Massi, L.; Queiroz, S. L.

pela descrição de todos os autores do artigo. O que também indica a apropriação do sistema de citações adotado em trabalhos científicos.

Outro trecho no qual Eduardo introduziu alterações para adequar o conteúdo do texto aos dados específicos do seu projeto pode ser visualizado no exemplo a seguir.

\begin{tabular}{|l|l|}
\hline \multicolumn{1}{|c|}{ Parágrafo do texto original } & Parágrafo do relatório de Eduardo - Primeira versão: \\
\hline $\begin{array}{l}\text { As células de leveduras foram suspensas em solu- } \\
\text { ção de nitrato de potássio (KNO3) } 10^{-4} \mathrm{M} \text {, variando } \\
\text { o pH e tampão Acetato } 0,05 \mathrm{M}, \text { no } \mathrm{pH} 4,5 .\end{array}$ & $\begin{array}{l}\text { As células de leveduras foram suspensas em solução de } \\
\text { nitrato de potássio (KNO3) } 10^{-4} \mathrm{M} \text { e no próprio meio defini- } \\
\text { do, foi variado o } \mathrm{pH} \text { de 1,5 a 7,5 e foram utilizados os hi- } \\
\text { drocarbonetos Hexano 95\%, Tolueno, p-Xileno e Octanol. }\end{array}$ \\
\hline
\end{tabular}

Nesse caso, observamos a inserção do trecho "foram utilizados os hidrocarbonetos Hexano 95\%, Tolueno, p-Xileno e Octanol", que era característico do trabalho de Eduardo. Destacamos ainda que, a partir da revisão de Pedro, essa informação foi separada da anterior em um novo subitem da seção materiais e métodos.

Sobre esse mesmo trecho, apresentamos, ainda, a segunda versão que Eduardo escreveu, com as partes novas destacadas, sendo que essa versão foi aceita como a versão definitiva, sem nenhuma correção de Pedro:

\section{Parágrafo do relatório final de Eduardo - Segunda versão:}

A hidrofobicidade foi obtida colocando $3 \mathrm{~mL}$ da suspensão de células em um tubo de ensaio e $1 \mathrm{ml}$ de hidrocarboneto, agita-se por 25 segundos (agitador de tubos) e deixa repousar por 10 minutos. Após a separação das fases foi medida a absorbância da fase inferior (solução aquosa contendo o restante das células), e determinado a concentração de células, em porcentagem, que aderiu ao solvente, utilizando-se da fórmula: $\mathrm{Hid}=[(\mathrm{Ci}-\mathrm{Cr}) .(\mathrm{Cr})-1] \times 100$

Onde, Ci é a concentração inicial da solução e Cr concentração residual, que é a concentração da suspensão após a mistura com o solvente.

Destacamos aqui outra forma de repetição histórica, na qual o aluno introduz a equação para determinação da hidrofobicidade, indicando o que cada termo significava na equação. Percebemos, pelo texto, que essa informação não se baseia em nenhuma referência. Quando questionamos Eduardo sobre a fonte da informação, a memória discursiva, ele apontou para seu cérebro, como poderíamos supor, visto que a memória discursiva se refere a sentidos já cristalizados. Percebemos, pela análise do caderno de laboratório, que o aluno usava a fórmula constantemente, como apresentamos na Figura 1, talvez, por isso, a assimilação tenha sido tão forte que ele nem se dava conta da fonte. Esse caso configura um exemplo de repetição histórica e exercício da função autor. 
Investigando processos de autoria na produção ...

Figura 1. Trecho do caderno de Eduardo, que evidencia o uso da equação para medida da hidrofobicidade que o aluno introduziu no seu relatório.

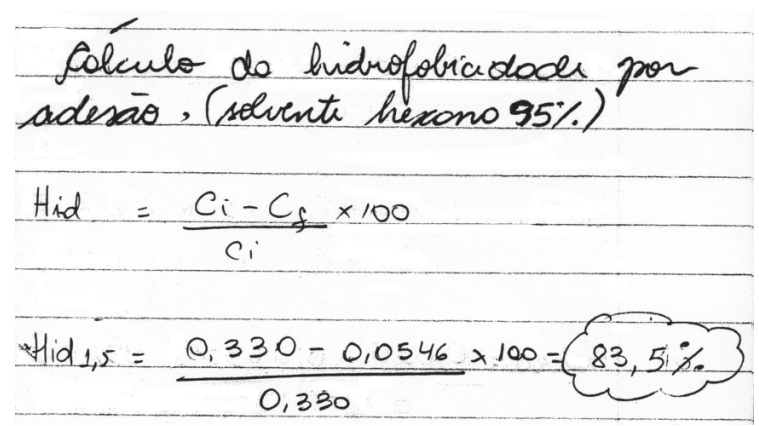

Fonte: As autoras.

Ressaltamos, ainda, que a opção do aluno por apresentar uma equação que não constava em nenhuma parte do relatório anterior pode revelar a forma de compreensão sobre o tema, própria desse aluno, ou sua visão de que um texto científico deve se apoiar na fundamentação matemática, que se materializa discursivamente pelo uso de equações, tabelas e gráficos. De qualquer forma, acreditamos que essa inserção seja uma evidência da apropriação da linguagem científica, apoiada na prática e na vivência do aluno na condução da sua pesquisa.

Observamos a inserção de outra equação no detalhamento do método de medida empregado pelo aluno, quando ele descreve o cálculo utilizado para a obtenção da concentração celular. Destacamos que, no trecho apresentado abaixo, toda a explicação procedimental apresentada antes da fórmula também foi redigida pelo aluno de forma livre, e que Pedro não introduziu nenhuma alteração no texto, o que indica a precisão científica das informações trazidas. Merece destaque, também, a preocupação do produtor do texto em indicar a marca e o modelo do equipamento utilizado. Uma vez que, desde o início das atividades de IC, independente de qualquer orientação de Pedro, o aluno tinha o costume de anotar esse tipo de informação no seu caderno de laboratório. Isso indica a contribuição do curso de graduação e das disciplinas práticas na sua preparação para as atividades de pesquisa.

Para a medida da concentração das suspensões, foram pegas alíquotas de $500 \mu \mathrm{L}$ de cada suspensão com os diferentes $p H s$, e diluídos com cinco partes de água destilada cada, em tubos de ensaio. Estas foram agitadas em agitador de tubos, e as absorbancias foram medidas em um espectrofotômetro da marca FEMTO 432 C. As concentrações foram calculadas pela fórmula:

$C=D \times A b s \times f$

Onde $\boldsymbol{D}$ é a diluição, Abs a Absorbância e $\boldsymbol{f}$ um fator (medida de massa seca) equivalente a 1,05. 
Massi, L.; Queiroz, S. L.

$\mathrm{Na}$ Figura 2, também apresentamos o trecho do caderno de laboratório, no qual destacamos a preocupação do aluno em usar a fórmula e especificar o significado de cada um dos seus componentes.

Figura 2. Trecho do caderno de Eduardo, que evidencia o uso da equação para medida da concentração celular que o aluno introduziu no seu relatório.

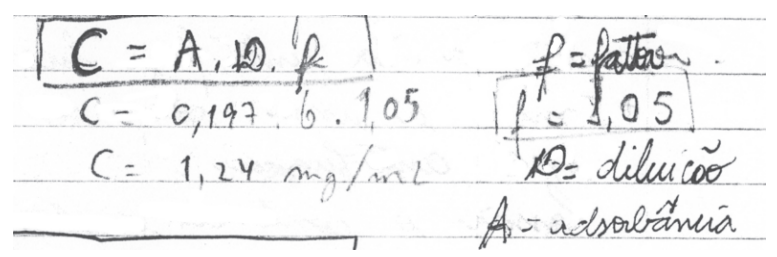

Fonte: As autoras.

A seção de resultados também foi construída de forma livre, indicando a primazia da repetição histórica, e se deu em várias etapas. O acompanhamento das alterações produzidas pelo aluno e por Pedro nos permite a visualização da apropriação e uso da linguagem científica pelo aluno de IC. Em função disso, analisamos essa seção em detalhes, tendo como base as alterações em cada etapa da produção e análise dos gráficos.

Como já havíamos comentado, a primeira etapa continha apenas os gráficos, com um título e uma legenda, no caso do primeiro gráfico, o título era TIF-13 - Tolueno - PM e a legenda trazia a seguinte informação "solução de TIF-13, no próprio meio com adição do bidrocarboneto hexano 95\%". Destacamos a opção do aluno por escrever, em todas as legendas dos gráficos, a palavra hidrocarboneto antes da apresentação do solvente, o que reforça a importância dessa informação para o produtor do texto. Outro aspecto comum aos gráficos foi o termo PM nos títulos, indicando próprio meio; essa construção da sigla não segue nenhum padrão do grupo de pesquisa e, portanto, representa uma construção pessoal do bolsista. Percebemos, ainda, que, nessa primeira versão, o aluno não teve a preocupação com a formatação da legenda.

Um aspecto que merece destaque em especial é o termo TIF-13, que aparece nas figuras em dois momentos diferentes: na legenda e no título do gráfico. Esse termo foi alterado na segunda etapa, visto que essa é a forma como o grupo de pesquisa conhece a levedura que foi registrada sob o nome FLT-01, que vem da palavra flotante. É interessante notar que Eduardo estava sempre envolvido com atividades práticas e registro de dados envolvendo o termo TIF-13, mas, como ainda não tinha produzido nenhum texto, não conhecia a denominação mais adequada para a levedura. Essa substituição foi indicada por Pedro, e Eduardo alterou o termo no texto que vinha abaixo do gráfico, mas manteve TIF-13 no título dos gráficos e na tabela com os dados dos gráficos que Eduardo solicitou, como podemos perceber na Figura 3, que traz a segunda etapa de produção do texto. 
Investigando processos de autoria na produção ...

Figura 3. Exemplo de um dos gráficos da segunda etapa de produção dos resultados e discussão do relatório de Eduardo.

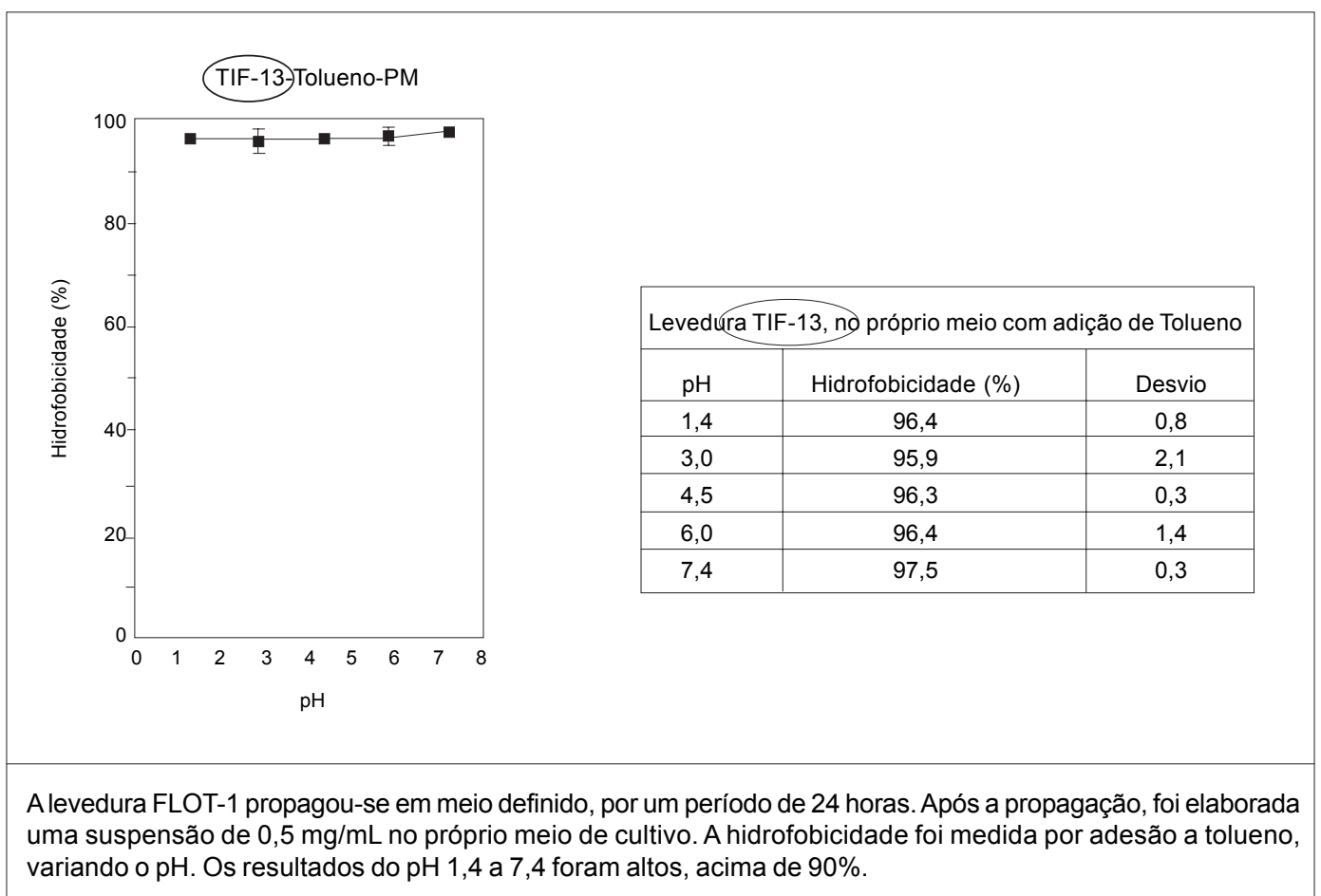

Fonte: As autoras.

Percebemos, nessa nova etapa, o resultado das considerações de Pedro, sobre a inserção da tabela, e a descrição dos parâmetros das medidas. Destacamos, novamente, os termos TIF-13 e FLOT-01; nessa etapa, o aluno substituiu o termo da forma correta, por FLT-01, apenas no primeiro gráfico, mas, nos demais, ele passou a escrever FLOT-01, visto que essa é a forma como os membros do laboratório pronunciam a sigla FLT, não como letras isoladas, mas como flot, que seria uma abreviação da palavra flotante. Acreditamos que essa é mais uma marca da importância da prática na construção de sentidos no interior de uma formação discursiva determinada, no caso específico, a do grupo de pesquisa.

Passando para a análise do texto apresentado na Figura 3, destacamos a presença da informação sobre o período de propagação da levedura, na passagem "por um período de vinte e quatro horas". Esse período havia sido alvo de confusões na condução dos experimentos, o que, provavelmente, marcou o aluno a ponto de ter elegido essa informação para dar ênfase no texto, no nível intradiscursivo; essa ênfase se revelou pelo destaque dessa como a primeira informação do trecho e pelo fato de o aluno escrever o número por extenso, enquanto todos os outros números do mesmo trecho estavam apresentados na forma de algarismos. Além da ênfase dada pelo aluno, nossa impressão de que ele deu destaque a essa informação foi confirmada pela correção de Pedro, que será apresentada a seguir na discussão da terceira etapa de produção e análise dos gráficos. 
Massi, L.; Queiroz, S. L.

Nesse mesmo trecho do texto apresentado na Figura 3, percebemos outra marca do papel da prática na construção de sentidos, por meio da análise da segunda sentença "após a propagação foi elaborada uma suspensão de $0,5 \mathrm{mg} / \mathrm{mL}$ no próprio meio de cultivo", na qual observamos uma descrição metodológica, inclusive na forma de passos, sendo um, apresentado na primeira sentença, após o outro, da sentença em questão. Ainda sobre essa sentença, destacamos a preocupação na quantificação da concentração de células que já havia sido apresentada na seção materiais e métodos.

Na terceira etapa da produção e análise dos gráficos da seção resultados e discussão, Pedro sugeriu novas alterações no texto original, apresentado na Figura 3, como podemos perceber pela transcrição dessa nova etapa apresentada a seguir.

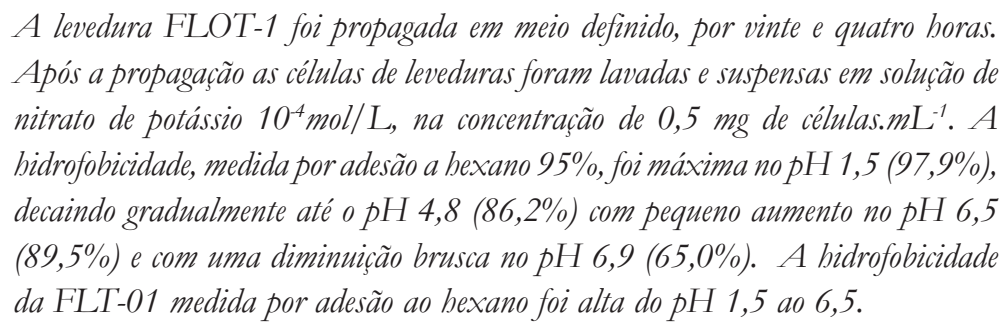

Destacamos que o coorientador sugeriu a retirada da informação um período de quando o aluno informa sobre o tempo de propagação, o que reforça nossa impressão do destaque que o aluno deu ao período de tempo. Outra substituição que remete à linguagem científica foi a troca da voz ativa em propagou-se - que dava a visão errada de que a levedura se propagou sozinha - pela voz passiva em foi propagada, no sentido de que o pesquisador a propagou. Observamos, ainda nesse trecho, a inserção de novas informações sobre a variação dos pontos no gráfico, advindas da análise desse e favorecidas pela presença da tabela.

Observamos, no arquivo referente a essa etapa, que apenas o primeiro gráfico foi revisado por Pedro, sendo que os demais traziam as novas diretrizes sobre a descrição do gráfico, mas mantinham alguns erros, como a grafia FLOT e a expressão propagou-se. Destacamos, na descrição da variação dos outros gráficos - como as apresentadas abaixo - feita por Eduardo, o uso de termos próprios, que não são muito comuns na descrição de gráficos, como ascendendo, decaindo e linearidade.

Sendo assim a bidrofobicidade minima foi de 36,3\% no $p H$ 3,0, ascendendo ao seu máximo em 70,1\% no pH 6,0 e decaindo até 56,6\% no pH 7,1. [...]

As hidrofobicidades iniciais demonstram certa linearidade, 81,9\% no $p H$ 1,4, 82,7\% no pH 3,0, 82,6\% no pH 4,4, decaindo até 56,0\% no pH 7,1, passando por $77,5 \%$ no $p H 7,1$.

Alguns dados referentes ao uso do solvente octanol exigiam maiores explicações, por parte do aluno, referentes às observações experimentais. Nas etapas de produção do texto já comentadas, o aluno introduziu essas informações por meio do seguinte trecho: 
Investigando processos de autoria na produção ...

Após a mistura da suspensão com o bidrocarboneto, parte do solvente se mostrou na forma de micro partículas na solução, isto pode ter alterado o resultado da medida de absorbância. Isto explica a medida de hidrofobicidade baixa observada no gráfico.

Esse trecho foi alterado na quarta etapa, quando o aluno incluiu informações que poderiam justificar as observações experimentais, destacadas no trecho abaixo, novamente inserindo o interdiscurso, novo neste caso, porém fruto da memória discursiva, no trecho que já era novo, já era fruto de uma repetição histórica, pois ele mesmo o havia produzido. Além dessa inserção, observamos a repetição formal no início desse trecho, visando melhor compreensão das informações veiculadas. Apresentamos, a seguir, o trecho reformulado na quarta etapa e mantido como tal até a versão definitiva.

$\mathrm{Na}$ mistura da solução com octanol, parte do solvente se mostrou na forma de micro partículas na solução, devido a pequena polaridade da molécula, pois contém um grupo com densidade de carga negativa $\left(\mathrm{HO}^{-}\right)$. Isto pode ter alterado o resultado da medida de absorbância explicando a medida de hidrofobicidade baixa, observada no gráfico.

Acreditamos que a inserção da justificativa apresentada pelo aluno tenha surgido a partir de discussões com Pedro, já que ele não cita nenhuma referência. A inserção dessas informações também revela adequação ao discurso científico, que pretende apresentar justificativas para fenômenos observados com base no corpo teórico da ciência (OLIVEIRA; QUEIROZ, 2007).

No nosso ponto de vista, essa foi a alteração mais significativa nessa quarta etapa. Outra mudança sugerida pelo coorientador foi a inversão das informações apresentadas nos resultados e discussão, ao contrário do modo como o aluno havia organizado: Pedro pediu que ele colocasse os dados referentes à solução de nitrato de potássio antes dos dados referentes ao próprio meio. Na penúltima etapa, o aluno retirou algumas informações que se repetiam no início de um conjunto de gráficos e, por meio de subtítulos, apresentou um parágrafo que fosse comum aos gráficos do conjunto logo no início, deixando, embaixo das tabelas, apenas a descrição das variações nos valores obtidos. Ainda nessa etapa, observamos a repetição histórica a partir da análise dos gráficos por meio da inserção de dois trechos no texto. $\mathrm{O}$ primeiro tipo de inserção surgiu ao final de cada descrição, nas quais, seguindo as orientações de Pedro, o aluno tentou resumir os resultados observados, por meio de frases como: " $A$ bidrofobicidade da FLT-01 medida por adesão ao hexano foi alta do pH 1,5 ao 6,5"; ou "A hidrofobicidade da FLOT-1 por adesão a octanol foi baixa em todos os pontos do gráfico". O segundo tipo foi observado no término de cada subseção, nas quais o aluno analisou os gráficos no conjunto, produzindo trechos como os seguintes:

Podemos observar que os três primeiros gráficos apresentam medidas altas de hidrofobicidade cada um com sua particularidade. Os gráficos nos quais foram utilizados os solventes hexano e tolueno apresentaram certa familiaridade, porque ambos no inicio, tem altas medidas e tem os finais num declínio brusco. [...] 
Massi, L.; Queiroz, S. L.

Com exceção do último gráfico, todos os outros apresentam certa semelhança, dentre eles destaca-se a semelhança entre os gráficos com bexano e p-xileno pelas curvas de bidrofobicidade muito parecidas que os dois apresentam.

A última etapa segue as correções de Pedro. Na maioria dos casos, ele substitui palavras e expressões visando melhorar a clareza das informações e a precisão científica, mas, além disso, ele escreveu as legendas dos gráficos e das figuras e produziu alguns trechos que foram introduzidos no relatório da mesma forma como ele mesmo havia escrito. Podemos citar como exemplos de correção: os termos FLOT-01 e TIF-13 trocados por FLT-01, como já havíamos comentado; variando o $p H$ por em função do $p H$; demonstram certa linearidade por foram lineares; moderada por média; entre outras.

Citamos apenas um exemplo de um trecho alterado por Pedro no qual ele acrescentou informações relacionadas à flotação (destacadas na transcrição apresentada abaixo), que Eduardo não pesquisou e que, portanto, não poderia correlacionar; destacamos, também, que Pedro introduz uma citação do seu grupo de pesquisa (apresentada como refpara proteger a identidade dos sujeitos da pesquisa). Essas alterações representam exemplos de uma visão global do tema de pesquisa que dificilmente o aluno teria trabalhando apenas no seu projeto de pesquisa.

\begin{tabular}{|c|c|}
\hline Parágrafo do relatório de Eduardo & Parágrafo do relatório de Eduardo corrigido por Pedro \\
\hline $\begin{array}{l}\text { Podemos observar que os três primeiros gráfi- } \\
\text { cos apresentam medidas altas de hidrofobicida- } \\
\text { de cada um com sua particularidade. Os gráfi- } \\
\text { cos nos quais foram utilizados os solventes he- } \\
\text { xano e tolueno apresentaram certa familiaridade, } \\
\text { porque ambos no início tem altas medidas e tem } \\
\text { os finais num declínio brusco. }\end{array}$ & $\begin{array}{l}\text { Podemos observar que os três primeiros gráficos apresen- } \\
\text { tam medidas altas de hidrofobicidade acima de } 75 \% \text {. Esta } \\
\text { linhagem, apresenta alta flotação, sendo a hidrofobicidade, } \\
\text { um princípio básico da flotação, os dados de hidrofobicidade } \\
\text { da Saccharomyces cerevisiae correspondem a flotação apre- } \\
\text { sentada por esta linhagem, no próprio meio e também quan- } \\
\text { do lavada e suspensa em solução salina (ref) }\end{array}$ \\
\hline
\end{tabular}

O objetivo, bem como as discussões e considerações finais, foram produzidos por Eduardo e Pedro em conjunto. Nas discussões e considerações, observamos a retomada dos principais resultados obtidos, sem a inserção de novas informações que justificassem os resultados. Pudemos acompanhar o processo de elaboração dos objetivos pela gravação dos diálogos no laboratório, e percebemos que os dois construíram o texto juntos, mas Pedro já tinha um modelo preestabelecido para essa seção. $O$ texto final dos objetivos foi apresentado da seguinte forma: "O objetivo deste trabalho é avaliar a hidrofobicidade das células de leveduras por adesão a bidrocarbonetos variando linhagens de leveduras, hidrocarbonetos e meios". Apresentamos, a seguir, os referidos diálogos que levaram à produção desse texto: 
Investigando processos de autoria na produção ...

\begin{tabular}{|c|c|}
\hline Pedro & $\begin{array}{l}\text { "O objetivo do trabalho é avaliar a hidrofobicidade das células de levedura por adesão a diferentes } \\
\text { hidrocarbonetos". }\end{array}$ \\
\hline Eduardo & $\begin{array}{l}\text { E os meios não falam nada? E se a gente colocar aqui, diferentes hidrocarbonetos em diferentes } \\
\text { meios? }\end{array}$ \\
\hline Pedro & $\begin{array}{l}\text { É. No final dá, em diferentes meios... é, "o objetivo do trabalho é avaliar a hidrofobicidade das } \\
\text { células de levedura por adesão a diferentes hidrocarbonetos em diferentes meios" ponto final. }\end{array}$ \\
\hline Eduardo & É só isso? [espantado] \\
\hline Pedro & Fala outro objetivo. \\
\hline Eduardo & Não sei! \\
\hline Pedro & [risos] \\
\hline Eduardo & Objetivo pode ser tão pequenininho assim? \\
\hline Pedro & É. \\
\hline Eduardo & $\begin{array}{l}\text { Mas lá na conclusão a gente comparou também a hidrofobicidade entre elas né? Nos meios? Até } \\
\text { que a LTU... }\end{array}$ \\
\hline Pedro & $\begin{array}{l}\text { Então, tá, mas avaliar a hidrofobicidade... o "o objetivo do trabalho é avaliar a hidrofobicidade das } \\
\text { células de levedura por adesão a diferentes hidrocarbonetos em diferentes"... nossa! Muito } \\
\text { diferente! "o objetivo do trabalho é avaliar a hidrofobicidade das células de levedura por adesão a } \\
\text { hidrocarbonetos"... vamos por "o objetivo do trabalho é avaliar a hidrofobicidade das células de } \\
\text { levedura por adesão a hidrocarbonetos variando as leveduras, os hidrocarbonetos e os meios" } \\
\text { pode ser? }\end{array}$ \\
\hline Eduardo & Hidrocarbonetos e variando... \\
\hline Pedro & Variando, variando leveduras ou linhagem de leveduras? \\
\hline Eduardo & Linhagem de leveduras. \\
\hline
\end{tabular}

\section{Considerações finais}

De maneira geral, acreditamos que, mesmo tendo copiado algumas partes do relatório da bolsista anterior, pelo funcionamento da repetição formal, o aluno compreendeu a maior parte do texto e operou com a gramática de forma a aprimorar a redação do relatório. Nos trechos em que observamos a repetição histórica, percebemos o desenvolvimento da compreensão do tema de pesquisa e da autonomia do aluno, ao escrever os trechos de forma livre, mas trazendo, pela via da memória discursiva, informações corretas e específicas para sua pesquisa. A partir das correções que o coorientador fez no texto, percebemos o sucesso do aluno nas operações descritas. Em nossa análise, destacamos, ainda, a distinção entre deslocamentos de sentidos que não apontavam para o sentido original do texto. Nossa preocupação se apoia na própria constituição do discurso científico que não permite uma grande abertura para a inserção de novos sentidos. Desta forma, consideramos que, apesar de o trabalho do aluno, algumas vezes, deslocar o "já-dito" (ORLANDI, 2004), ele se manteve atrelado às regras do discurso científico.

Dessa forma, tanto o uso da repetição empírica e formal, que se mantém atrelada à rigidez do discurso científico, quanto o uso da repetição histórica, na qual se exerce a função autor e podem ser produzidos novos conhecimentos científicos, apontam para um uso da linguagem científica de acordo com a formação discursiva própria da área. Essa percepção 
Massi, L.; Queiroz, S. L.

nos sugere a apropriação da linguagem científica pelo aluno, dada, essencialmente, pela experiência da prática da pesquisa vivenciada diariamente no laboratório. Encontramos, ao longo da análise, marcas que sugerem e confirmam nossa conclusão.

\section{Referências}

BRIDI, J. C. A. A iniciação científica na formação do universitário. 2004. 135 f.

Dissertação (Mestrado em Educação) - Faculdade de Educação, Universidade Estadual de Campinas, Campinas, 2004.

CORACINI, M. J. Um fazer persuasivo: o discurso subjetivo da ciência. Campinas: Pontes, 1991.

FOUCAULT, M. A ordem do discurso. 11. ed. São Paulo: Loyola, 2004.

MASSI, L.; QUEIROZ, S. L. Estudos sobre iniciação científica no Brasil: uma revisão.

Cadernos de Pesquisa, São Paulo, v. 40, n. 139, p. 174-197, 2010.

OLIVEIRA, J. R. S.; QUEIROZ, S. L. Comunicação e linguagem científica: guia para estudantes de química. Campinas: Átomo, 2007.

ORLANDI, E. P. Discurso e leitura. 5. ed. São Paulo: Cortez, 2000.

Análise do discurso: princípios e procedimentos. 5. ed. Campinas: Pontes, 2003. Interpretação: autoria, leituras e efeitos do trabalho simbólico. 4. ed. Petrópolis: Vozes, 2004.

QUEIROZ, S. L.; ALMEIDA, M. J. P. M. Do fazer ao compreender ciências: reflexões sobre o aprendizado de alunos de iniciação científica em química. Ciência \& Educação, Bauru, v. 10, n. 1, p. 41-53, 2004.

Artigo recebido em 15/08/2011. Aceito em 06/02/2012. 